\title{
PENGARUH GAYA KEPEMIMPINAN DAN BUDAYA ORGANISASI TERHADAP KINERJA KARYAWAN PADA UNIVERSITAS MUHAMMADIYAH TANGERANG
}

\author{
Rabitha Fazira S.H., M.M. \\ Dudung Hadi Wijaya S.E., MM \\ Fakultas Ekonomi dan Bisnis \\ Universitas Muhammadiyah Tangerang
}

\begin{abstract}
ABSTRAK
Tujuan penelitian dilakukan untuk mengetahui apakah terdapat analisis pengaruh Gaya Kepemimpinan dan Budaya Organisasi terhadap Kinerja Karyawan Universitas Muhammadiyah Tangerang. Methode penelitian yang digunakan adalah methode penelitian Survei. Responden adalah Karyawan pada Universitas Muhammadiyah Tangerang. Type penelitian ini adalah penelitian penjelasan (explanatory research), karena penelitian ini menjelaskan pengaruh Gaya Kepemimpinan dan Budaya Organisasi terhadap Kinerja Karyawan. Pengumpulan data dilakukan melalui kuisioner. Analisis data menggunakan analisis regresi berganda.

Hasil penelitian menunjukan bahwa pengaruh Gaya Kepemimpinan dan Budaya Organisasi terhadap Kinerja Karyawan, dengan kontribusi determinasi $\left(\mathrm{R}^{2}\right)$ sebesar 0,590 atau 59,0\%, Dijelaskan oleh variabel lain diluar konsep penelitian dan persamaan regresi yang dihasilkan adalah $\hat{\mathrm{Y}}=5,325+0,528 \mathrm{X}_{1}+0,321 \mathrm{X}_{2}$.

Berdasrkan persamaan regresi diatas maka dapat dijelaskan, Dengan nilai konstanta ( $\left.b_{0}\right)$ sebesar 5,325, menyatakan bahwa nilai Kinerja Karyawan akan tetap ada sebesar 5,325 walaupun variabel bebasnya Gaya Kepemimpinan, dan Budaya Organisasi tidak ada (0). Nilai $\left(b_{1}\right)$ sebesar 0,528 , ini berarti menunjukan ada pengaruh positif dan signifikan variabel Gaya Kepemimpinan terhadap Kinerja Karyawan sebesar 0,528, jika nilainya positif berarti kalau ada peningkatan sebesar 0,528 maka kinerja karyawanpun akan meningkat sebesar 0,528. Nilai $\left(b_{2}\right)$ sebesar 0,321 ini menunjukan bahwa ada pengaruh positif dan signifikan Budaya Organisasi terhadap Kinerja Karyawan sebesar yaitu sebesar 0,321, jika Budaya Organisasi meningkat sebesar 0,321 maka Kinerja Karyawan juga akan meningkat sebesar yang sama yaitu 0,321 maka Kinerja Karyawan akan meningkat dengan jumlah yang sama.
\end{abstract}

\section{Latar Belakang}

Dalam sebuah organisasi baik kecil maupun besar tidak dapat dipisahkan dari peran sumber daya manusia. Tanpa sumber daya manusia maka organisasi tidak akan tumbuh dan berkembang. Sumber daya manusia yang dimaksud adalah karyawan dari level bawah sampai manajemen puncak (top management).

Keberhasilan suatu organisasi dipengaruhi oleh kinerja karyawan (job perfomance) atau hasil kerja yang dicapai oleh seorang karyawan dalam melakukan tugas dan tanggung jawab yang diberikan kepadanya.Karyawan merupakan sumber daya manusia yang penting bagi organisasi, arena memiliki bakat, tenaga dan kreativitas yang sangat dibutuhkan oleh organisasi untuk mencapai tujuannya.

Undang-undang ketenaga kerjaan pada tahun 2003 pasal 1 ayat 1 ketenaga kerjaan adalah segala hal yang berhubungan dengan tenaga kerja pada waktu sebelum , selama, dan sesudah masa kerja.

Karyawan merupakan kunci penentu keberhasilan instansi. Setiap karyawan selain dituntut untuk memiliki pengetahuan, keteram pilan dan kemampuan, juga harus mempunyai pengalaman, motivasi, disiplin diri, dan semangat kerja tinggi, sehingga jika kinerja karyawan baik maka kinerja instansi juga akan meningkat ynag menuju pada pencapaian tujuan instansi.

Peningkatkan kinerja karyawan akan membawa kemajuan bagi instansi untuk dapat bertahan dalam suatu persaingan lingkungan bisnis yang tidak stabil. Oleh karena itu, upaya-upaya untuk meningkatkan kinerja karyawan merupakan tantangan manajemen yang paling serius karena keberasihan untuk mencapai tujuan dan kelangsungan hidup instansi tergantung pada kualitas sumber daya manusia yang ada didalamnya.

Kinerja karyawan yang tinggi sangatlah diharapkan oleh setiap instansi. Semakin banyak karyawan yang mempunyai kinerja yang tinggi, maka produktivitas instansi secara keseluruhan akan meningkat sehingga instansi akan dapat bertahan dalam persaingan global. Karyawan dituntut untuk menyelesaikan tugas dan tanggung jawabnya secara efektif dan efisien. Keberhasilan karyawan dapat diukur melalui kepuasan komsumen, berkurangnya jumlah keluhan dan tercapai target yang optimal.

Saat ini banyak karyawan baru di Universitas Muhammadiyah Tangerang tidak adanya rekrutmen yang cukup lama menyebabkan adanya gap yang jauh antara senior dengan junior. Seharusnya dengan karyawan baru ini bisa dimanfaatkan de ngan baik karena ada energi baru yang masih produktif. Tetapi karena lemahnya peranan budaya organisasi dan juga leadershif menyebabkan kinerja karyawan baru ini dirasa kurang maksimal akibat transfer ilmu dan knowledge yang lambat.

Seorang pemimpin tidak hanya fokus pada target instansi tetapi jauh dari pada itu seorang pemimpin harus membangun hubungan yang baik dengan bawahanya agar terciota kondisi kerja yang nyaman sehngga karyawan bisa memberikan kinerja yang lebih maksimal. Kepemimpinan berperan dalam memperkuat dan mengubah budaya organisasi. Seorang pemimpin menjadi teladan bagi bawahannya dalam menjaga budaya organisasi. Banyak organisasi saat ini merasa perlu untuk mengubah budaya organisasi guna menjamin kelangsungan hidupnya atau untuk memperoleh manfaat yang lebih kompetitif. Hal ini sering didorong oleh 
kenyataan bahwa budaya yang telah ada kadang tidak lagi mampu memperbaiki keadaan masa datang seperti yang dibutuhkan organisasi.

Kekuatan-kekuatan dalam lingkungan eksternal organisasi dapat mengisyaratkan kebutuhan perubahan budaya, misalnya dengan adanya persaingan yang makin tajam dalam suatu lingkungan organisasi/instansi menurut perubahn organisasi untuk senantiasa mampu merespon keingina pelanggan (custumer) dengan lebih cepat. Disamping berasal dari lingkungan eksternal, kekuatan perubahan budaya juga bisa berasal dari dalam /internal.

\section{Metode Penelitian}

Data kuantitatif yaitu penelitian kuantitatif yang berdasarkan studi deskriptif dimana penelitian ini berhubungan dengan masalah-masalah berupa fakta-fakta saat ini. Analisis kuantitatif merupakan analisis yang digunakan terhadap data yang berwujud angka-angka dan cara pembahasannya dalam penelitian ini menggunakan aplikasi program SPSS (Statistic Pakcagge for the Sosial Science) Versi 22. Penelitian dilakukan dengan cara datang langsung pada Universitas Muhammadiyah Tangerang dimana penulis melakukan penelitian dan melakukan interview serta observasi yang berkaitan dengan permasalahan serta meminta dokumen-dokumen pendukung sebagai bahan untuk melengkapi penulisan.

\section{Uji Hipotesis}

\section{a.Uji Asumsi Klasik}

Untuk mengetahui kesalahan model regresi yang digunakan dalam penelitian, maka terlebih dahulu harus dilakukan pengujian asumsi klasik sebagai berikut:

\section{1) Uji Normalitas Data}

Uji normalitas ini bertujuan untuk menguji apakah dalam model regresi variabel pengganggu atau residual memiliki distribusi normal. Seperti diketahui bahwa uji t dan $\mathrm{F}$ mengasumsi bahwa nilai residual mengikuti distribusi normal. Ada dua cara untuk mendekteksi apakah residual berdistribusi normal atau tidak yaitu dengan analisis grafik dan uji statistik (Ghozali, 2011 : 160).

Gambar 4.1

Uji Normalitas Data

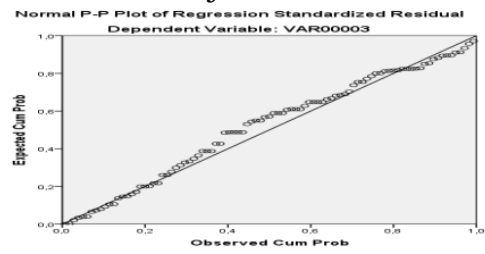

Dari gambar di atas terlihat bahwa sebaran data mengikuti garis diagonal, maka model regresi tersebut memenuhi asumsi normalitas atau berdistribusi normal.

Tabel 4.1

Hasil uji normalitas instrumen penelitian

One-Sample Kolmogorov-Smirnov Test

\begin{tabular}{|c|c|c|c|c|}
\hline & & $\begin{array}{c}\text { Gaya } \\
\text { Kepemi } \\
\text { mpinan }\end{array}$ & $\begin{array}{c}\text { Budaya } \\
\text { Organisasi }\end{array}$ & $\begin{array}{c}\text { KinerjaKa } \\
\text { ryawan }\end{array}$ \\
\hline $\begin{array}{l}\text { N } \\
\text { Normal } \\
\text { Parameters }{ }^{\mathrm{a}, \mathrm{b}} \\
\text { Most } \\
\text { Extreme } \\
\text { Differences } \\
\text { Kolmogorov-Smi }\end{array}$ & $\begin{array}{l}\text { Mean } \\
\text { Std. } \\
\text { Deviation } \\
\text { Absolute } \\
\text { Positive } \\
\text { Negative } \\
\text { lov Z }\end{array}$ & $\begin{array}{r}93 \\
39,0538 \\
5,15913 \\
\\
, 123 \\
, 123 \\
-, 110 \\
\\
1,183\end{array}$ & $\begin{array}{r}93 \\
38,8280 \\
4,68954 \\
\\
, 133 \\
, 133 \\
-, 090 \\
1,278\end{array}$ & $\begin{array}{r}93 \\
38,4086 \\
4,82123 \\
, 172 \\
, 091 \\
-, 172 \\
1,663\end{array}$ \\
\hline
\end{tabular}

Asymp. Sig. (2-tailed)

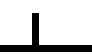

a. Test distribution is Normal.

b. Calculated from data.

Sumber: Output SPSS V.22.0

Dari tabel di atas, didapatkan hasil uji normalitas dengan uji one sample kolmogorov-smirnov $z$, diperoleh nilai kolmogorov-smirnov z Gaya Kepemimpinan $\left(\mathrm{X}_{1}\right)$ sebesar $1,183>0,05$, nilai kolmogorov-smirnov $z$ untuk variabel Budaya Organisasi $\left(\mathrm{X}_{2}\right)$ sebesar $1,278>0,05$, nilai kolmogorov-smirnov $z$ test untuk variabel Kinerja Karyawan (Y) sebesar 1,663 > 0,05.

Dari hasil tersebut di atas, oleh karena nilai kolmogorovsmirnov $z$ Gaya Kepemimpinan $\left(\mathrm{X}_{1}\right)$, nilai kolmogorovsmirnov $z$ untuk variabel Budaya Organisasi $\left(\mathrm{X}_{2}\right)$, dan nilai kolmogorov-smirnov z $l$ lebih besar dari 0,05 ( 5\%) dan untuk variabel Kinerja Karyawan (Y) lebih besar dari 0,05 ( $5 \%$ ), maka data tersebut dikatakan mempunyai distribusi normal untuk $\mathrm{X}_{1}, \mathrm{X}_{2}$ dan $\mathrm{Y}$ atau memenuhi persyaratan normalitas.

\section{2) Uji Heteroskedastisitas}

Uji heteroskedastisitas bertujuan untuk menguji apakah dalam model regresi terjadi ketidaksamaan varians dari residual satu pengamatan kepengamatan yang lain. Jika varians dari residual satu pengamatan ke pengamatan lain tetap, maka disebut homoskedatisitas. Model regresi yang baik adalah homoskedastisitas atau tidak terjadi heteroskedasitas (Ghazali, 2011 : 139)

\section{Gambar 4.2}

Grafik Scatterplot Uji Heteroskedastisitas scatterplot

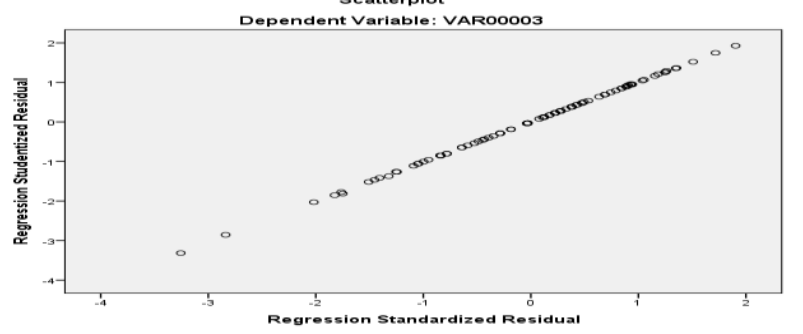

Berdasarkan gambar di atas melalui Scatterplot menggambarkan bahwa distribusi data menyebar secara acak dan tidak membentuk suatu pola tertentu baik di atas maupun di bawah angka 0 pada sumbu Y dan distribusi data penelitian ini acak dan tidak membentuk pola tertentu dan dengan demikian dapat dikatakan bahwa model regresi dalam penelitian ini tidak terjadi heterokesdastisitas dan layak digunakan dalam penelitian.

\section{3) Multikolinearitas}

Uji multikolinearitas bertujuan untuk apakah model regresi ditemukan adanya korelasi antara variabel bebas (independen). Model regresi yang baik seharusnya tidak terjadi korelasi di antara variabel independen. Hasil pengujian multikolonieritas dapat dilihat berdasarkan Variance Inflation Factor (VIF), jika nilai VIF > 10 maka dapat disimpulkan terjadi multikolonieritas. Sebaliknya, jika nilai VIF < 10 maka dapat disimpulkan tidak terjadi multikolonieritas. Berikut ini adalah hasil uji multikolonieritas.

Tabel 4.2

Rekapitulasi nilai tolerance untuk uji collinearity Coefficients $^{\mathbf{a}}$

Model

\begin{tabular}{|c|c|}
\hline \multicolumn{2}{|c|}{ Collinearity Statistics } \\
\hline Tolerance & VIF \\
\hline
\end{tabular}




\begin{tabular}{|ll|r|r|}
\hline & (Constant) & & \\
1 & Gaya Kepemimpinan &, 759 & 1,317 \\
& Budaya Organisasi &, 759 & 1,317 \\
\hline
\end{tabular}

a. Dependent Variable: Kerja

Sumber: SPSS 22

Berdasarkan tabel di atas dapat diketahui bahwa pada kolom VIF dari masing-masing variabel independen tidak memiliki nilai yang lebih dari 10, sehingga dapat disimpulkan bahwa model regresi dalam penelitian ini tidak terjadi multikolonieritas.

b. Model Regresi Linear

1) Uji Regresi Linear Sederhana

Uji regresi Linear sederhana ini dilakukan untuk mengetahui arah hubungan antara variabel independen (X) dengan variabel dependen (Y) apakah positif atau negatif dan memprediksi nilai dari variabel dependen. Apabila nilai variabel independen mengalami kenaikan atau penurunan maka, berdasarkan perhitungan SPSS 22 dapat diperoleh sebagai berikut:

Tabel 4.3

Regresi Linear Sederhana Variabel Gaya Kepemimpinan $\left(\mathrm{X}_{1}\right)$ terhadap Tingkat Kinerja Karyawan (Y)

\begin{tabular}{|ll|r|r|r|r|}
\hline \multirow{2}{*}{ Model } & \multicolumn{2}{|c|}{$\begin{array}{c}\text { Unstandardized } \\
\text { Coefficients }\end{array}$} & \multicolumn{1}{c|}{ Sig. } \\
\cline { 2 - 6 } & \multicolumn{1}{|c|}{ B } & Std. Error & & \\
\hline \multirow{2}{*}{1} & (Constant) & 12,190 & 2,684 & 4,541 &, 000 \\
& Gaya Kepemimpinan &, 671 &, 068 & 9,852 &, 000 \\
\hline
\end{tabular}

Sumber: Data Primer yang diolah menggunakan SPSS 22, 2017

Berdasarkan tabel 4.3 diperoleh koefisien persamaan regresi Linear sederhana sebagai berikut:

$$
Y=12,190+0,671 X_{1}
$$

Penjelasan persamaan tersebut adalah sebagai berikut:

a) Konstanta sebesar 12,190; artinya jika Gaya Kepemimpinan nilainya 0 maka, tingkat Kinerja Karyawan nilainya sebesar 12,190.

b) Koefisien regresi Gaya Kepemimpinan sebesar 0,671; artinya bila Gaya Kepemimpinan mengalami satu satuan maka, Kinerja Karyawan akan mengalami peningkatan sebesar 0,671 satuan dengan asumsi variabel independen lainnya yang bernilai tetap.

Tabel 4.4

Regresi Linear Sederhana Variabel Budaya Organisasi $\left(\mathrm{X}_{2}\right)$ terhadap Tingkat Kinerja Karyawan (Y)

\begin{tabular}{|ll|r|r|r|r|}
\hline \multirow{2}{*}{ Model } & \multicolumn{2}{|c|}{ Unstandardized Coefficients } & \multirow{2}{*}{ Sig. } & Sig. \\
\cline { 2 - 4 } & \multicolumn{1}{|c|}{ B } & Std. Error & & \\
\hline \multirow{2}{*}{1 (Constant) } & 14,889 & 3,405 & 4,372 &, 000 \\
& Budaya Organisasi &, 606 &, 087 & 6,956 &, 000 \\
\hline
\end{tabular}

Sumber: Data Primer yang diolah menggunakan SPSS 22, 2017

Berdasarkan tabel 4.4 diperoleh koefisien persamaan regresi Linear sederhana sebagai berikut:

$$
\mathrm{Y}=\mathbf{1 4 , 8 8 9}+\mathbf{0 , 6 0 6 \mathrm { X } _ { 2 }}
$$

Penjelasan persamaan tersebut adalah sebagai berikut:

a) Konstanta sebesar 14,889; artinya jika Gaya Kepemimpinan nilainya 0 maka, tingkat Kinerja Karyawan nilainya sebesar 14,889 .

b) Koefisien regresi Gaya Kepemimpinan sebesar 0,606; artinya bila Gaya Kepemimpinan mengalami satu satuan maka, Kinerja Karyawan akan mengalami peningkatan sebesar 0,606 satuan dengan asumsi variabel independen lainnya yang bernilai tetap.

\section{2) Uji Regresi Linear Berganda}

Uji regresi Linear berganda dilakukan untuk mengetahui arah hubungan antara variabel independen $\left(\mathrm{X}_{1}\right.$ dan $\left.\mathrm{X}_{2}\right)$ dengan variabel dependen (Y) apakah masing-masing variabel independen berhubungan positif atau negatif dan memprediksi nilai dari variabel dependen. Apabila nilai variabel independen mengalami kenaikan atau penurunan maka, berdasarkan perhitungan SPSS 21 dapat diperoleh hasil sebagai berikut:

Tabel 4.5

Regresi Linear Berganda Variabel Gaya Kepemimpinan $\left(\mathrm{X}_{1}\right)$ dan Budaya Organisasi $\left(\mathrm{X}_{2}\right)$ Terhadap Tingkat Kinerja Karyawan (Y).

\begin{tabular}{|ll|r|r|r|r|}
\hline \multirow{2}{*}{ Model } & \multicolumn{2}{|c|}{$\begin{array}{c}\text { Unstandardized } \\
\text { Coefficients }\end{array}$} & \multicolumn{1}{c|}{ Sig. } & \\
\cline { 2 - 6 } & \multicolumn{1}{|c|}{ B } & \multicolumn{1}{|c|}{ Std. Error } & & \\
\hline \multirow{2}{*}{1} & (Constant) & 5,325 & 3,014 & 1,767 &, 081 \\
Gaya Kepemimpinan &, 528 &, 072 & 7,300 &, 000 \\
& Budaya Organisasi &, 321 &, 080 & 4,025 &, 000 \\
\hline
\end{tabular}

Sumber: Data Primer yang diolah menggunakan SPSS 22, 2017

Berdasarkan tabel 4.5 diperoleh koefisien persamaan regresi Linear sederhana sebagai berikut:

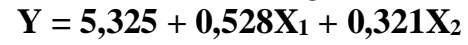

Penjelasan persamaan tersebut adalah sebagai berikut:

a) Koefisien sebesar 5,325; artinya Jika Gaya Kepemimpinan dan Budaya Organisasi nilainya 0 maka, Tingkat Kinerja Karyawan nilainya sebesar 5,325 .

b) Koefisien regresi variabel Gaya Kepemimpinan 0,528; artinya Jika Gaya Kepemimpinan mengalami satusatuan maka, Tingkat Kinerja Karyawan akan mengalami peningkatan sebesar 0,528 satuan dengan asumsi variabel independen lainnyan yang bernilai tetap.

c) Koefisien regresi variabel Budaya Organisasi 0,321; artinya Jika Pengatahuan Wajib mengalami satusatuan maka, Tingkat Kinerja Karyawan akan mengalami peningkatan sebesar 0,321 satuan dengan asumsi variabel independen lainnyan yang bernilai tetap.

\section{3) Uji Korelasi Sederhana}

Uji Korelasi Sederhana digunakan untuk mengetahui arah hubungan yang terjadi ditunjukkan pada tabel 4.6 dan tabel 4.7 sebagai berikut:

Tabel 4.6

Hasil Uji Korelasi Sederhana Variabel Gaya Kepemimpinan $\left(\mathrm{X}_{1}\right)$ Terhadap Tingkat Kinerja Karyawan

\begin{tabular}{|c|c|c|c|c|c|c|}
\hline \multirow{2}{*}{$\begin{array}{l}\text { Mo } \\
\text { del }\end{array}$} & \multirow[t]{2}{*}{$\mathrm{R}$} & \multirow{2}{*}{$\begin{array}{c}\text { R } \\
\text { Squar } \\
\mathrm{e}\end{array}$} & \multirow{2}{*}{$\begin{array}{l}\text { Adjuste } \\
\text { d R } \\
\text { Square }\end{array}$} & \multirow{2}{*}{$\begin{array}{l}\text { Std. Error } \\
\text { of the } \\
\text { Estimate }\end{array}$} & \multicolumn{2}{|c|}{ Change Statistics } \\
\hline & & & & & $\begin{array}{c}\mathrm{R} \\
\text { Square } \\
\text { Change }\end{array}$ & $\begin{array}{c}\mathrm{F} \\
\text { Change }\end{array}$ \\
\hline 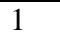 &, $718^{\mathrm{a}}$ &, 516 & ,511 & 3,37216 &, 516 & 97,056 \\
\hline
\end{tabular}

(Y)

Model Summary ${ }^{\mathrm{b}}$

Sumber: Data Primer yang diolah menggunakan SPSS 22, 2017

Berdasarkan Tabel diatas diketahui bahwa $\mathrm{R}$ (Korelasi) dari Variabel Gaya Kepemimpinan $\left(\mathrm{X}_{1}\right)$ terhadap Tingkat Kinerja Karyawan (Y) sebesar 0,718. Korelasi antara 
variabel tersebut dinyatakan baik.

Tabel 4.7

Hasil Uji Korelasi Sederhana Variabel Budaya Organisasi $\left(\mathrm{X}_{2}\right)$ Terhadap Tingkat Kinerja Karyawan (Y)

\begin{tabular}{|c|c|c|c|c|c|c|}
\hline \multirow{2}{*}{$\begin{array}{l}\text { Mo } \\
\text { del }\end{array}$} & \multirow[t]{2}{*}{$\mathrm{R}$} & \multirow{2}{*}{$\begin{array}{c}\mathrm{R} \\
\text { Squar } \\
\mathrm{e}\end{array}$} & \multirow{2}{*}{$\begin{array}{c}\text { Adjuste } \\
\text { d R } \\
\text { Square }\end{array}$} & \multirow{2}{*}{$\begin{array}{l}\text { Std. Error of } \\
\text { the Estimate }\end{array}$} & \multicolumn{2}{|c|}{ Change Statistics } \\
\hline & & & & & $\begin{array}{c}\mathrm{R} \\
\text { Square } \\
\text { Change }\end{array}$ & $\begin{array}{c}\mathrm{F} \\
\text { Change }\end{array}$ \\
\hline 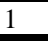 &, $589^{\mathrm{a}}$ & ,347 &, 340 & 3,91690 & ,347 & 48,386 \\
\hline
\end{tabular}

Sumber: Data Primer yang diolah menggunakan SPSS 22, 2017

Berdasarkan tabel diatas diketahui bahwa nilai $\mathrm{R}$ (Korelasi) sebesar 0,589. Korelasi antara variabel tersebut dinyatakan baik.

\section{4) Uji Korelasi Berganda}

Hasil uji korelasi berganda untuk variabel $\left(\mathrm{X}_{1}\right)$ dan $\left(\mathrm{X}_{2}\right)$ terhadap variabel terikat (Y).

$$
\text { Tabel } 4.8
$$

Hasil Uji Korelasi Berganda Variabel Gaya Kepemimpinan $\left(\mathrm{X}_{1}\right)$ dan Budaya Organisasi $\left(\mathrm{X}_{2}\right)$ Terhadap Tingkat Kinerja Karyawan (Y) Model Summary $^{\mathrm{b}}$

\begin{tabular}{|c|c|c|c|c|c|c|}
\hline \multirow{2}{*}{$\begin{array}{l}\text { Mo } \\
\text { del }\end{array}$} & \multirow[t]{2}{*}{$\mathrm{R}$} & \multirow{2}{*}{$\begin{array}{c}\mathrm{R} \\
\text { Squar } \\
\mathrm{e}\end{array}$} & \multirow{2}{*}{$\begin{array}{l}\text { Adjuste } \\
\text { d R } \\
\text { Square }\end{array}$} & \multirow{2}{*}{$\begin{array}{l}\text { Std. Error of } \\
\text { the Estimate }\end{array}$} & \multicolumn{2}{|c|}{ Change Statistics } \\
\hline & & & & & $\begin{array}{c}\mathrm{R} \\
\text { Square } \\
\text { Change }\end{array}$ & $\begin{array}{c}\mathrm{F} \\
\text { Change }\end{array}$ \\
\hline 1 &, $768^{\mathrm{a}}$ &, 590 & ,581 & 3,12146 & ,590 & 64,738 \\
\hline
\end{tabular}

Sumber: Data Primer yang diolah menggunakan SPSS 22, 2017

Berdasarkan tabel diatas diketahui bahwa $\mathrm{R}$ (korelasi) dari variabel Gaya Kepemimpinan dan Budaya Organisasi terhadap tingkat Kinerja Karyawan sebesar 0,768. Korelasi antara variabel tersebut dinyatakan tinggi.

\section{Uji $\mathbf{R}^{2}$ (Koefisien Determinasi)}

Hasil nilai adjusted R-Square dari regresi digunakan untuk mengetahui besarnya struktur Kinerja Karyawan yang dipengaruhi variabel-variabelnya adalah sebagai berikut:

\section{Tabel 4.9}

Hasil Uji Koefisien Determinasi Model Summary $^{\mathrm{b}}$

\begin{tabular}{|c|c|c|c|c|c|c|}
\hline \multirow{2}{*}{$\begin{array}{l}\text { Mo } \\
\text { del }\end{array}$} & \multirow[t]{2}{*}{$\mathrm{R}$} & \multirow{2}{*}{$\begin{array}{c}\mathrm{R} \\
\text { Squar } \\
\mathrm{e}\end{array}$} & \multirow{2}{*}{$\begin{array}{c}\text { Adjuste } \\
\text { d R } \\
\text { Square }\end{array}$} & \multirow{2}{*}{$\begin{array}{l}\text { Std. Error of } \\
\text { the Estimate }\end{array}$} & \multicolumn{2}{|c|}{ Change Statistics } \\
\hline & & & & & $\begin{array}{c}\text { R } \\
\text { Square } \\
\text { Change }\end{array}$ & $\begin{array}{c}\mathrm{F} \\
\text { Change }\end{array}$ \\
\hline 1 &, $768^{\mathrm{a}}$ & ,590 & ,581 & 3,12146 &, 590 & 64,738 \\
\hline
\end{tabular}

Sumber: Data Primer yang diolah menggunakan SPSS 22, 2017

Berdasarkan tabel diatas menunjukkan bahwa koefisien determinasi yang ditunjukkan dari nilai R-Square sebesar 0,590 atau $59,0 \%$ yang menunjukkan bahwa tingkat Kinerja Karyawan pada Universitas Muhammadiyah Tangerang dipengaruhi oleh variabel Gaya Kepemimpinan dan Budaya Organisasi. Sisanya 41,0\% dipengaruhi oleh variabel lain yang tidak diteliti dalam penelitian ini. Diharapkan penelitian selanjutnya menggunakan variabel lain yang belum peneliti ambil dalam penulisan skripsi ini.

\section{Uji Statistik t (t-test)}

Uji statistik $\mathrm{t}$ digunakan untuk mengetahui ada atau tidaknya pengaruh masing-masing variabel independen secara individual terhadap variabel dependen yang di uji pada tingkat signifikan 0,05 atau tingkat kepercayaan 95\% dengan kriteria pengujian:

Jika $t_{\text {hitung }} \geq t_{\text {tabel }}$, maka $\mathrm{H}_{\mathrm{o}}$ ditolak dan $\mathrm{H}_{\mathrm{a}}$ diterima.

Jika $t_{\text {hitung }} \leq t_{\text {tabel }}$, maka $\mathrm{H}_{\mathrm{o}}$ diterima dan $\mathrm{H}_{\mathrm{a}}$ ditolak.

Dibawah ini dapat dilihat hasil uji t yang penulis dapatkan dari hasil pengolahan SPSS 22 adalah sebagai berikut:

Tabel 4.10

Hasil Uji t

\begin{tabular}{|c|r|r|}
\hline Model & $\mathrm{t}$ & \multicolumn{2}{|c|}{ Sig. } \\
\hline (Constant) & 1,767 &, 081 \\
Gaya Kepemimpinan & 7,300 &, 000 \\
Budaya Organisasi & 4,025 &, 000 \\
\hline
\end{tabular}

Sumber: Data Primer yang diolah menggunakan SPSS 22, 2017

\section{a. Uji Koefisien Regresi Variabel Gaya Kepemimpinan $\left(\mathbf{X}_{1}\right)$}

Berdasarkan tabel diatas $\mathrm{t}$ hitung untuk variabel Gaya Kepemimpinan $\left(\mathrm{X}_{1}\right)$ sebesar 7,300 dengan tingkat signifikan 0,000 . Nilai probabilitas $(0,000)$ lebih kecil dari 0,05 maka, model regresi dapat dipakai untuk memprediksi tingkat Kinerja Karyawan sedangkan, untuk tabel distribusi t dicari $\alpha=5 \%$ (Uji 2 sisi) dengan derajat kebebasan (df) n-k1 atau 93-2 = 91 (n adalah jumlah data dan $\mathrm{k}$ adalah jumlah variabel independen). Dengan pengujian 2 sisi (signifikansi $=0,05$ ) hasil diperoleh untuk $\mathrm{t}$ tabel untuk variabel penerapan Gaya Kepemimpinan $\left(\mathrm{X}_{1}\right)$ yaitu 1,296 (tabel t statistik), dimana;

$\mathrm{H}_{\mathrm{o}}$ :Tidak terdapat pengaruh positif dan signifikan antara Gaya Kepemimpinan terhadap tingkat Kinerja Karyawan pada Universitas Muhammadiyah Tangerang.

$\mathrm{H}_{\mathrm{a}}$ :Terdapat pengaruh positif dan signifikan antara penerapan Gaya Kepemimpinan terhadap tingkat Kinerja Karyawan pada Universitas Muhammadiyah Tangerang.

Jadi, nilai $\mathrm{t}$ hitung $>\mathrm{t}$ tabel $(7,300>1,296)$ maka, $\mathrm{H}_{\mathrm{o}}$ ditolak dan $\mathrm{H}_{\mathrm{a}}$ diterima. Hal ini menunjukkan bahwa variabel independen yaitu Gaya Kepemimpinan secara parsial berpengaruh positif dan signifikan terhadap variabel dependen yaitu tingkat Kinerja Karyawan. Nilai t hitung positif artinya pengaruh yang terjadi adalah positif. Dengan demikian hipotesis menyatakan bahwa:

$\mathrm{H}_{2}$ : Terdapat pengaruh positif dan signifikan antara Gaya Kepemimpinan terhadap tingkat Kinerja Karyawan pada Universitas Muhammadiyah Tangerang.

\section{b. Uji Koefisien Regresi Variabel Budaya Organisasi} $\left(\mathbf{X}_{2}\right)$

Berdasarkan tabel diatas $\mathrm{t}$ hitung untuk variabel Budaya Organisasi $\left(\mathrm{X}_{2}\right)$ sebesar 4,025 dengan tingkat signifikan 0,000 . Nilai probabilitas $(0,000)$ lebih kecil dari 0,05 maka, model regresi dapat dipakai untuk memprediksi tingkat Kinerja Karyawan sedangkan, untuk tabel distribusi t dicari $\alpha=5 \%$ (Uji 2 sisi) dengan derajat kebebasan (df) n-k1 atau 93-2 =91 ( $\mathrm{n}$ adalah jumlah data dan $\mathrm{k}$ adalah jumlah variabel independen). Dengan pengujian 2 sisi (signifikansi $=0,05$ ) hasil diperoleh untuk t tabel untuk variabel pengetahuan $\left(\mathrm{X}_{2}\right)$ yaitu 1,296 (tabel t statistik), dimana;

$\mathrm{H}_{\mathrm{o}}$ :Tidak terdapat pengaruh positif dan signifikan antara Budaya Organisasi terhadap tingkat Kinerja Karyawan 
pada Universitas Muhammadiyah Tangerang;

$\mathrm{H}_{\mathrm{a}}$ :Terdapat pengaruh positif dan signifikan antara Budaya Organisasi terhadap tingkat Kinerja Karyawan pada Universitas Muhammadiyah Tangerang.

Jadi, nilai $\mathrm{t}$ hitung $>\mathrm{t}$ tabel $(4,025>1,296)$ maka, $\mathrm{H}_{\mathrm{o}}$ ditolak dan $\mathrm{H}_{\mathrm{a}}$ diterima. Hal ini menunjukkan bahwa variabel independen yaitu Budaya Organisasi secara parsial tidak berpengaruh positif dan signifikan terhadap variabel dependen yaitu tingkat Kinerja Karyawan. Nilai t hitung positif artinya tidak ada pengaruh yang positif. Dengan demikian hipotesis menyatakan bahwa:

$\mathrm{H}_{2}$ : Tidak terdapat pengaruh positif dan signifikan antara Budaya Organisasi terhadap tingkat Kinerja Karyawan pada Universitas Muhammadiyah Tangerang.

\section{Uji Statistik F (F-test))}

Pada dasarnya menunjukkan apakah semua variabel bebas Gaya Kepemimpinan dan Budaya Organisasi yang dimasukan dalam model mempunyai pengaruh secara bersama-sama terhadap variabel terikat tingkat Kinerja Karyawan. Pengujian hipotesis F digunakan untuk melihat apakah secara simultan atau keseluruhan variabel bebas mempunyai pengaruh yang positif terhadap variabel variabel terikat. Pengujian dilakukan dengan taraf signifikan 0,05 atau 95\% dengan kriteria pengujian: Jika $\mathrm{F}_{\text {hitung }} \geq \mathrm{F}_{\text {tabel }}$ maka, $\mathrm{H}_{\mathrm{o}}$ ditolak dan $\mathrm{H}_{\mathrm{a}}$ diterima; Jika $\mathrm{F}_{\text {hitung }} \leq \mathrm{F}_{\text {tabel }}$ maka, $\mathrm{H}_{\mathrm{o}}$ diterima dan $\mathrm{H}_{\mathrm{a}}$ ditolak.

\section{Tabel 4.11}

Hasil Uji F

ANOVA $^{\mathrm{a}}$

\begin{tabular}{|c|c|c|c|c|c|}
\hline Model & $\begin{array}{l}\text { Sum of } \\
\text { Squares }\end{array}$ & $\mathrm{df}$ & $\begin{array}{l}\text { Mean } \\
\text { Square }\end{array}$ & $\mathrm{F}$ & Sig. \\
\hline Regression & 1261,555 & 2 & 630,778 & 64,738 &, $000^{\mathrm{b}}$ \\
\hline $1 \quad$ Residual & 876,918 & 90 & 9,744 & & \\
\hline Total & 2138,473 & 92 & & & \\
\hline
\end{tabular}

a. Dependent Variable: KinerjaKaryawan

b. Predictors: (Constant), Budaya Organisasi, Gaya

Kepemimpinan

Sumber: Data Primer yang diolah menggunakan SPSS 22, 2017

Dari tabel diatas didapat $\mathrm{F}$ hitung sebesar 64,738 dengan tingkat signifikansi 0,000 . Nilai probabilitas $(0,000)$ lebih kecil 0,05 maka, model regresi dapat dipakai untuk memprediksi tingkat Kinerja Karyawan . Hasil F hitung tersebut jika dibandingkan dengan $\mathrm{F}$ tabel pada tingkat keyakinan $75 \%(\alpha=0,05)$, df 1 (Jumlah variabel -1$)$ atau 3-1 = 2 dan df 2 (n-k-1) atau 93-2-1= 90 (n adalah jumlah data dan $\mathrm{k}$ adalah jumlah variabel independen). Dengan pengujian 2 sisi (signifikansi $=0,05$ ) hasil diperoleh $\mathrm{F}$ tabel adalah sebesar 3,150 (tabel F statistik), dimana;

$\mathrm{H}_{03}$ : Tidak terdapat pengaruh positif dan signifikan secara simultan antara Gaya Kepemimpinan dan Budaya Organisasi terhadap tingkat Kinerja Karyawan pada Universitas Muhammadiyah Tangerang;

$\mathrm{H}_{\mathrm{a} 3}$ :Terdapat pengaruh positif dan signifikan secara simultan antara Gaya Kepemimpinan dan Budaya Organisasi terhadap tingkat Kinerja Karyawan pada Universitas Muhammadiyah Tangerang.

Jika nilai $\mathrm{F}$ hitung $>\mathrm{F}$ tabel $(64,738>3,150)$ maka, $\mathrm{H}_{\mathrm{o}}$ ditolak dan $\mathrm{H}_{\mathrm{a}}$ diterima. Hal ini menunjukkan bahwa variabel independen yaitu Gaya Kepemimpinan $\left(\mathrm{X}_{1}\right)$ dan
Budaya Organisasi $\left(\mathrm{X}_{2}\right)$ berpengaruh positif dan signifikan terhadap variabel dependen yaitu tingkat Kinerja Karyawan (Y). Dengan demikian hipotesis menyatakan bahwa:

$\mathrm{H}_{\mathrm{a} 3}$ :Terdapat pengaruh positif dan dignifikan secara simultan antara Gaya Kepemimpinan dan Budaya Organisasi terhadap tingkat Kinerja Karyawan pada Universitas Muhammadiyah Tangerang.

\section{B. Pembahasan hasil Penelitian}

1. Berdasarkan analisis yang telah dilakukan dengan menggunakan SPSS V 22 diperoleh hasil bahwa secara simultan variabel bebas yaitu Gaya Kepemimpinan dan Budaya Organisasi memiliki pengaruh yang signifikan terhadap kinerja karyawan di Universitas Muhammadiyah Tangerang.

2. Hasil pengujian hipotesis secara individual (Uji t) diperoleh nilai signifikansi untuk variabel Gaya Kepemimpinan sebesar 0,000 lebih kecil 0,05 yang berarti Gaya Kepemimpinan berpengaruh signifikan terhadap kinerja karyawan.

3. Hasil pengujian hipotesis secara individual (Uji t) diperoleh nilai signifikansi untuk variabel Budaya Organisasi sebesar 0,000 lebih kecil 0,05 yang berarti Budaya Organisasi berpengaruh signifikan terhadap kinerja karyawan. Dengan demikian seorang karyawan perlu memiliki Budaya Organisasi yang terus diupayakan instansi untuk menunjang kemajuan instansi.

4. Hasil pengujian secara simultan menunjukan nilai signifikansi sebesar 0,000 lebih kecil 0,05. Hal ini mengandung arti bahwa kedua variabel bebas yaitu Gaya Kepemimpinan dan Budaya Organisasi berpengaruh signifikan terhadap kinerja karyawan.

\section{DAFTAR PUSTAKA}

1) Ghozali, Imam (2011). Aplikasi Analisis Multivariate Dengan Program SPSS. Semarang. Badan Penerbit UNDIP.

2) Hasibuan, Malayu, 2014. Managjemen Sumber Daya Manusia, edisi XVIII, Bumi Aksara.

3) Hasibuan, Melayu SP, (2011), Manajemen Sumber Daya Manusia, Edisi Revisi, Jakarta, Bumi Aksara

4) Herlambang, Susatyo. 2013. Pengantar Manajemen Cara Mudah Memahami Ilmu Manajemen. Yogyakarta : Pustaka Baru.

5) Hery. 2013. Cara Cepat dan Mudah Memahami Pengantar Manajemen. Yogyakarta : Gava Media

6) Kohli, A. K, Shervani, T.A, and Challagalla, 1998, Learning and Performance Oreintation of Salespoeple: The Role of Supervisor, Journal of Marketing, vol 35, AS.

7) Luthans, Fred, 2006, Perilaku Organisasi, Andi Offset, Yogayakarta.

8) Mangkunegara Anwar Prabu, 2013, Manajemen Sumber Daya ManusiInstansi, Cetakan Keduabelas, Pt. Remaja Rosdakarya, Bandung

9) Mangkunegara, A.A.Anwar Prabu, 2014, Evaluasi Kiner Sumber Daya Manusia, PT. Refika Aditama Bandung.ugioyono. 2013. Metode Penelitian Kuantitatif Kualitatif dan R\&D Penerbit: ALFABETA,CV Jl Gegerkalong Hilir No.84 Bandung. 
10)Mangkunegara, Anwar Prabu (2004). Manajemen Sumber Daya Manusia, Remaja Rosdakarya, Bandung.

11)Mangkunegara, Anwar Prabu (2005). Manajemen Sumber Daya ManusiaInstansi, Rosda Karya, Bandung.

12)S Hasibuan, Malayu, 2005. Organisasi dan Motivasi.Jakarta : PT. Bumi Aksara.

15). Sugiyono. 2013. Metode Penelitian Kuantitatif Kualitatif dan R\&D Penerbit: ALFABETA,CV Jl Gegerkalong Hilir No.84 Bandung. 